\title{
Despedida de la profesora Teresa Eminowicz-Jaśkowska
}

El día 17 de julio se añadió otra necrológica a la historia de los estudios de Románicas de Cracovia, que en los últimos tiempos ha perdido a varios de sus representantes más ilustres: Anna Drzewicka, Witold Mańczak y Stanisław Widłak. A este círculo se ha unido Teresa Eminowicz-Jaśkowska (nacida el 29 de enero de 1938), quien durante sus estudios de Filología Románica (1956-1961) aprovechó la oportunidad, única en aquel tiempo, de completar su formación en la especialidad de Hispánicas, en el marco del seminario de máster de la profesora Stefania Ciesielska-Borkowska, nacida en Lwów y autora de la primera tesis de habilitación en literatura hispánica. También allí, en la Universidad Jan Kazimierz, había comenzado la carrera el catedrático Zygmunt Czerny, romanista e hispanista (tradujo el Quijote junto con su mujer, Anna Ludwika Czerny, y editó, añadiendo un epílogo, obras de Calderón), quien apoyó a la autora de Mistycyzm hiszpański na gruncie polskim (Misticos españoles en tierras polacas, 1939) en su tarea de abrir la sección de Hispánicas en el Instituto de Filología Románica. Ambos trasladaron a Cracovia la tradición de los estudios de románicas de Lwów, a los que el profesor Edward Porębowicz, educado en amplios horizontes humanistas, había dado forma (añadimos que Anna Nikliborc, su asistente, contribuyó a que surgieran también en Wrocław) y que estaban abiertos al patrimonio de todos los países de lenguas con raíz latina, no exclusivamente a Francia. Cuando el timón del Instituto de Filología Románica lo tomó en sus manos la catedrática Maria Strzałkowa, romanista, pero a la vez investigadora de las relaciones hispanopolacas, autora del primer manual de literatura española (1966) publicado después de la guerra, comenzaron los esfuerzos, coronados con éxito, de apertura de una especialidad independiente que formara a futuros divulgadores de la lengua de Cervantes.

La decisión ministerial que establece la Filología Hispánica en Cracovia le permitió a Teresa Eminowicz reorientar su carrera profesional, quien hasta ese momento había sido lectora de francés en la Escuela Superior de Arte Dramático en Cracovia (PWST - Państwowa Wyższa Szkoła Teatralna, actualmente Akademia Sztuk Teatralnych im. Stanisława Wyspiańskiego) y acumulaba una experiencia didáctica en educación primaria y secundaria de más de diez años. En noviembre de 1974 el Instituto de Filología Románica la contrata 
primeramente como lectora para ayudar en la organización de Hispánicas. De este modo consigue la oportunidad de avanzar en su carrera científica en la especialidad elegida en la universidad, finalizada con la tesis de máster, Lope de Vega en los escenarios polacos, y comienza a trabajar en una tesis doctoral sobre el Naturalismo en España, para la que, bajo la dirección de la profesora Strzałkowa, desde hacía algunos años había estado recopilando materiales durante varias becas de estudios en Francia. En ese momento nadie podía prever en qué circunstancias dramáticas tendría lugar la inauguración de la nueva especialidad y qué papel representaría en su mantenimiento. Poco después de la admisión de los primeros estudiantes, en agosto de 1975, la autora de Studia polsko-hiszpańskie (Estudios hispano-polacos) muere repentinamente y a partir de octubre la licenciada Eminowicz, ascendida al puesto de asistente, debe asumir la responsabilidad de su formación. Se le asigna una cantidad excesiva de horas didácticas, incluidos temas que debe además prepararse para poder impartir, así como cuestiones organizativas y de programación de la nueva especialidad, que debe cargar sobre sus hombros. Después de cambiar el tema, un doctorado surgido en estas condiciones solo puede llegar a materializarse en 1982. La tesis con el título de Hiszpania połowy XVII wieku — ideały i rzeczywistość w prozie Złotego Wieku (La España de mediados del siglo XVII. Ideales y realidad en la prosa del Siglo de Oro) es dirigida por la profesora Janina Z. Klave, filóloga portuguesa de la Universidad de Varsovia.

Los años anteriores a que la futura catedrática obtuviera la acreditación para poder impartir seminarios de máster la habían sustituido en esta tarea lingüistas de su Instituto de origen, principalmente el italianista Stanisław Widłak, así como colaboradores externos: la catedrática Gabriela Makowiecka de Madrid, pionera de los estudios eslavos en España, el Dr. Piotr Sawicki, de la Universidad de Wrocław, y la Dra. Jadwiga Konieczna-Twardzikowa, del Instituto de Lengua Polaca de la Academia Nacional de las Ciencias (Instytut Języka Polskiego PAN), quien a partir de ese momento y durante muchos años mantendría su labor unida a la Iberística de Cracovia. De las asignaturas troncales con los estudiantes de Hispánicas se ocupa también el catedrático Witold Mańczak, autor del manual Gramatyka hiszpańska (Gramática española); entre los profesores invitados se encuentran catedráticos de centros extranjeros e hispanistas polacos activos fuera de Polonia (Henryk Ziomek, Florian Śmieja). En los años siguientes, varios graduados en Románicas (Joanna Petry, Catherine Behnke, Bogdan Piotrowski) encuentran empleo temporal en Iberística; con puestos de mayor duración o permanentes se unen a la plantilla los primeros graduados en la nueva especialidad (Piotr Fornelski, Anna Sawicka, Jerzy Sławomirski) y sus compañeros de años posteriores (Artur Gromczakiewicz, Ewa Nawrocka, Maria Filipowicz).

Durante la solemne despedida de la profesora Eminowicz, que tuvo lugar el 23 de julio en el Cementerio de Rakowicki en Cracovia, el director del Instituto de Filología Románica de la Universidad Jaguelónica, el profesor Wacław Rapak, presentó el recorrido vital de la fallecida; en nombre de la 
Asociación de Hispanistas Polacos, tomó la palabra su alumna, la profesora Beata Baczyńska, de la Universidad de Wrocław, pero fueron las palabras pronunciadas por la profesora Ewa Nawrocka en nombre de los compañeros del Departamento de Filología Hispánica las que nos conmovieron profundamente a todos, y que nos permitimos citar aquí: "Hoy me despido de la profesora Teresa Eminowicz-Jaśkowska, la persona que me enseñó las primeras palabras en español, que me indicó las primeras lecturas de la literatura española. [...] Era una gran persona, amable con los compañeros y con los estudiantes. Era una gran maestra, la enseñanza era su misión; no solo enseñaba, sino que educaba exigiendo a los jóvenes responsabilidad, puntualidad, atención a las buenas maneras. [...] Cuando evocamos los momentos clave en la historia de los estudios de Iberística, no sólo en Cracovia —el primer simposio de iberistas, los inicios de las actividades de la Asociación Polaca de Hispanistas, las primeras publicaciones hispánicas, la primera habilitación y cátedra en la sección de Filología Hispánica en la Universidad Jaguelónica, el primer instituto de secundaria con un plan de estudios para la enseñanza del español- en todas partes vemos la labor y la iniciativa de la profesora Eminowicz-Jaśkowska. Y cuando recordamos todos estos logros, cuando vemos los hermosos frutos que su empeño ha cosechado, sentimos gratitud y respeto".

Volviendo al tema del trabajo de investigación de la profesora Eminowicz, recordemos que después de defender su doctorado, entre sus intereses académicos se encontraba en primer lugar la literatura de la Edad Media ( $U$ źródet hiszpańskiej prozy literackiej [Del origen de la prosa literaria española], 1994) y del Renacimiento (Hiszpański romans pasterski [Novela pastoril española], su tesis de habilitación, 1994). Retomó el Barroco, cuya prosa política, moralizante y didáctica ya había tratado en su tesis doctoral, con la monografía Baltasar Gracián. Hiszpański pisarz i moralista barokowy (Baltasar Gracián. Un escritor español y moralista barroco, 2003) que fue una parte esencial de los méritos para la solicitud del título de catedrática. Lo recibió siendo ya una investigadora reconocida en los círculos hispánicos europeos y una participante activa en muchos congresos internacionales, en constante expansión de su ámbito de influencia científica.

En el territorio nacional, la profesora Eminowicz luchó con sus publicaciones y declaraciones contra la ignorancia polaca sobre España, al mismo tiempo que tomaba medidas para difundir su literatura plurilingüe. Su mejor y fructífera semilla, a día de hoy aún activa, es la revista Studia Iberystyczne, iniciada por ella con el apoyo y la colaboración de la catedrática Urszula Dąmbska-Prokop. Su primera flor apareció en 1994; cinco años más tarde la revista ya había tomado forma de un anuario publicado con regularidad, con volúmenes monográficos dedicados a los ámbitos culturales del área de las lenguas iberorrománicas (con especiales sobre el gallego, el catalán, el portugués). Es imposible asimismo omitir el papel de la profesora en la aparición de la revista Estudios Hispánicos, que este año cumple su 30 aniversario, cuyos primeros volúmenes fueron el fruto de los Simposios Hispánicos Polacos. El 
primero, organizado por ella, tuvo lugar en Cracovia y Mogilany en diciembre de 1985 para conmemorar la primera década de la Iberística de Cracovia; el segundo (1990) y el tercero (1993), en Wrocław y Karpacz. Pensado como su continuación a escala internacional, el congreso "La Europa del Centro y del Este y el Mundo Hispánico" celebrado en octubre de 1995 en Cracovia, en el siguiente aniversario redondo de la creación de la especialidad con la que la profesora había unido su destino profesional, fue también, especialmente en la dimensión organizativa, obra de la profesora. Fueron muchas las iniciativas que tomó y que llevó a cabo con energía y coherencia. Lo primero que se debe mencionar es el establecimiento de una colaboración permanente de los hispanistas de Cracovia con la Universitat de Barcelona, en la que se comenzó el curso de lengua polaca como parte de los estudios eslavos que se estaban creando en ese momento. Ella también allanó el camino a sus sucesores, partiendo a Barcelona en 1987 por dos años, donde no solo enseñó la lengua, sino que también promovió la cultura polaca. En los estudios ibéricos en Cracovia, por otro lado, se creó como parte de un acuerdo interuniversitario el lectorado de lengua catalana (1986) y, a lo largo del tiempo, también las especialidades gallega y portuguesa. En diciembre de 1985, cuando se creó la Asociación Polaca de Hispanistas, la entonces doctora Eminowicz fue nombrada vicepresidenta de la Junta Directiva de APH, y en los últimos años también fue su presidenta. En su universidad de origen, dirigió desde el principio un equipo de docentes que enseñaban en la nueva especialidad, y desde 1996 en la recién creada Sección de Filología Hispánica; más tarde fue Subdirectora de Estudiantes en el Instituto de Filología Románica, y desde 2003 hasta la jubilación, su Directora. Haciéndose cargo del testigo en el relevo generacional tras sus maestras, Stefania Ciesielska-Borkowska y Maria Strzałkowa, se unió al reducido círculo de los pioneros de las "humanidades olvidadas", como describió una vez el profesor Stanisław Wędkiewicz los estudios ibéricos polacos.

Al despedirnos de la profesora con este breve recuerdo esbozado por personas que tuvieron el honor de trabajar con ella, nos gustaría volver a referirnos a las palabras pronunciadas en su entierro por Ewa Nawrocka: "Para concluir, me gustaría parafrasear el pensamiento de Baltasar Gracián, a quien tanto apreciaba nuestra profesora. Dice Gracián que quien muere joven sin alcanzar mucho en vida es un simple náufrago, pero a quien le fue dado vivir una larga, rica y fructífera vida arriba a puerto. Esta imagen hoy me consuela".

Piotr Sawicki

(Profesor Emérito de la Universidad de Wrocław)

Anna Sawicka (Universidad Jaguelónica) 